\title{
Heterologous expression of porcine reproductive and respiratory syndrome virus glycoprotein 5 in Bordetella bronchiseptica aroA mutant
}

\author{
Sang Ik PARK ${ }^{1)}$, Ja Young $\mathrm{SEO}^{1)}$ and Tae Jung $\mathrm{KIM}^{1)^{*}}$ \\ ${ }^{1)}$ College of Veterinary Medicine, Chonnam National University, Gwangju 500-757, Republic of Korea
}

(Received 30 November 2015/Accepted 13 June 2016/Published online in J-STAGE 24 June 2016)

ABSTRACT. Porcine reproductive and respiratory syndrome virus (PRRSV) is an economically important disease around the globe. Protection against this virus remains problematic. Here, we evaluated antibody (IgG \& IgA) inducibility of a heterologous PRRSV glycoprotein 5 (GP5) expressed in a live attenuated Bordetella bronchiseptica aroA mutant strain (BBS-GP5). Mice and pigs were primed with recombinant GP5 (rGP5) subcutaneously followed by boosting with live BBS-GP5. As a result, anti-GP5 IgG was induced in both mice $(P<0.001)$ and pigs $(P<0.1)$. Pigs were challenged with live PRRSV (VR2332). Viral RNA was found to be significantly $(P<0.01)$ removed in the vaccinated pig group. Overall, BBS-GP5 is a good candidate as a live attenuated vaccine against PRRSV infection.

KEY WORDS: attenuation, Bordetella bronchiseptica aroA, multivalent vaccine, porcine reproductive and respiratory syndrome virus

doi: 10.1292/jvms.15-0687; J. Vet. Med. Sci. 78(10): 1625-1629, 2016

Porcine reproductive and respiratory syndrome virus (PRRSV) is an enveloped RNA virus [17]. As an emerging pathogen, it is considered as one of the most economically important swine pathogens [17]. PRRSV core contains a $15 \mathrm{~kb}$ genome packaged in a capsid containing $14 \mathrm{kDa}$ nucleocapsid protein subunits. Of six structural proteins in the envelope, the most abundant proteins are $17 \mathrm{kDa}$ nonglycosylated membrane protein and $25 \mathrm{kDa}$ glycosylated glycoprotein 5 (GP5) as disulphide-linked heterodimers [7, 8]. GP5 appears to be a key viral structure. PPSRV attachment and entry to target cells could be mediated by GP5 or GP5-M heterodimers [4]. In addition, neutralization epitope of PRRSV is located in the middle of the GP5 ectodomain [9-11], and this GP5 was found to be immunogenic and useful as a candidate target for vaccine developments $[18,19]$. Currently, some modified live PRRSV vaccines are available. However, they offer protection against homologous strains, but are inconsistent and offer incomplete protection against heterologous strains [5], which requires constant vaccine developments.

It has been reported that Bordetella bronchiseptica can be attenuated through disrupting aromatic amino acid biosynthesis and used as live vaccines and vectors for heterologous antigens [14-16]. We have developed a mutant of $B$. bronchiseptica aro $A$ (BBS-aroA) and demonstrated that this strain is highly attenuated [6]. Unlike many other bacterial pathogens, $B$. bronchiseptica can colonize on healthy ciliated respiratory mucosa, making it highly infectious [6]. With this concept in mind, live vaccine derived from this

\footnotetext{
*CorresPondenceto:Kim,T.J.,CollegeofVeterinaryMedicine, Chonnam National University, 300 Yongbong-dong, Buk-gu, Gwangju 500-757, Republic of Korea. e-mail: tjkim@chonnam.ac.kr (C)2016 The Japanese Society of Veterinary Science

This is an open-access article distributed under the terms of the Creative Commons Attribution Non-Commercial No Derivatives (by-nc-nd) License $<$ http://creativecommons.org/licenses/by-nc-nd/4.0/>.
}

attenuated mutant strain has successfully delivered heterologous viral antigen to pigs [6]. Here, we developed an attenuated $\operatorname{aro} A$ mutant strain expressing a heterologous antigen (PRRSV GP5). The potential of this mutant strain as a PRSV vaccine was evaluated using immunological and challenge studies with mouse and pig models.

Escherichia coli, virus and plasmids: E. coli JM109 used to propagate plasmid construct was purchased from Invitrogen (Carlsbad, CA, U.S.A.). pGEM $^{\circledR}$-T Easy vector (Promega, Madison, WI, U.S.A.) was used in cloning procedures. E. coli manipulations were performed according to the manufacturer's instructions. Standard DNA and protein manipulations were carried out using published methods $[1,13]$. PRRSV VR2332 (Ingelvac, Boehringer Ingelheim Vetmedica Inc., St. Joseph, MO, U.S.A.) was used to prepare viral RNA.

Cloning strategy: Total RNA was prepared using Trizol ${ }^{\circledR}$ reagent (Invitrogen). cDNA was synthesized using SuperScript $^{\mathrm{TM}}$ III One-Step RT-PCR Systems (Invitrogen). Construct "pGEM-aroA-kan ${ }^{\mathrm{R}}$ [6]" was used as a "cassette holder" for generating an insert for homologous recombination (Fig. 1). A Red helper plasmid pKD46 [3] was used for homologous recombination. Primers used for GP5 gene cloning were designed to contain a $K p n I$ restriction site (GP5-F) and a BamHI restriction site (GP5-R) (Table 1). Polymerase chain reaction (PCR) products were purified using PCR purification kit (Qiagen, Hilden, Germany). Purified PCR products were cloned into $\mathrm{pGEM}^{\circledR}$-T Easy to generate pGEM-GP5. KpnI+BamHI $(\mathrm{K}+\mathrm{B})$ digested pGEM-GP5 ("cassette") was inserted into the $\mathrm{K}+\mathrm{B}$ site of pGEM-aroA$\mathrm{kan}^{\mathrm{R}}$ (cassette holder) to generate pGEM-aroA-kan ${ }^{\mathrm{R}}-\mathrm{GP} 5$. A linear DNA fragment (aroA-F-kan ${ }^{\mathrm{R}}-\mathrm{GP} 5$-aroA-R2: $1.68 \mathrm{~kb}$ ) was produced by digestion with $X h o \mathrm{I}$ and HindIII restriction enzymes. It was used as an insert $(100 \mathrm{ng} / \mu l)$ for homologous recombination. The cloning strategy is shown in Fig. 1.

Gene disruption by homologous recombination: Electrocompetent cells were prepared as described previously [6]. 


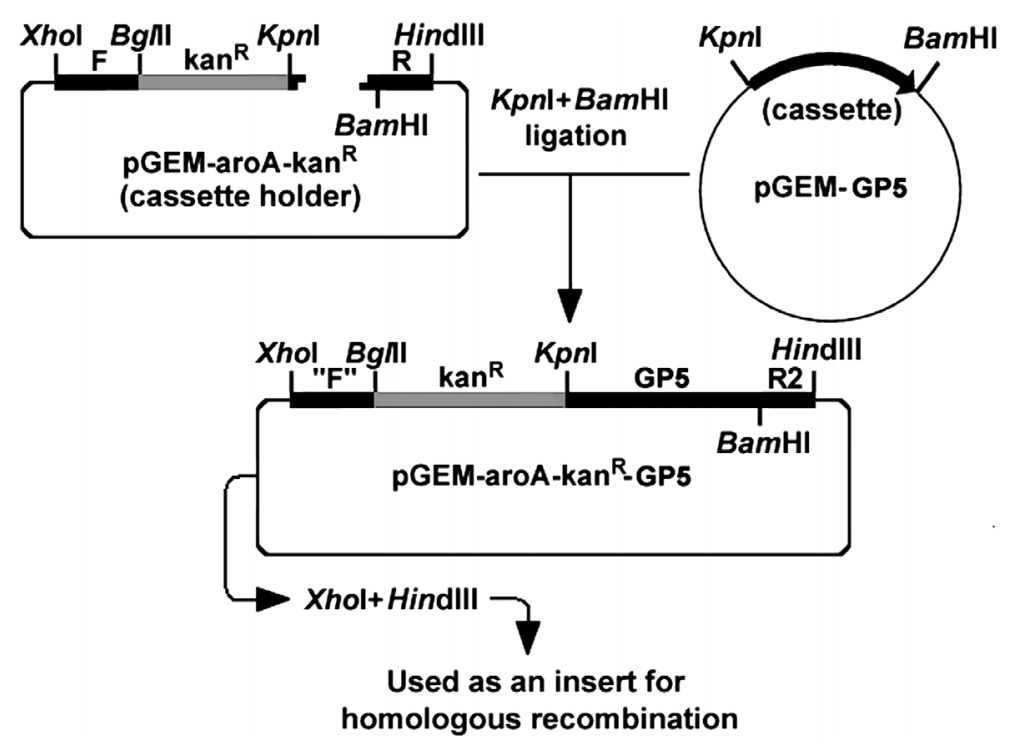

Fig. 1. Diagram of cloning strategy.

Table 1. Primers for cloning, PCR verification and quantitative real-time PCR

\begin{tabular}{|c|c|c|}
\hline Primers & Nucleotide sequence $\left(5^{\prime} \rightarrow 3^{\prime}\right)$ & GenBank \# \\
\hline GP5-F & AATT-GGTACC ${ }^{\text {a) }}$-ATGAGCAACGACAGCAGCTCCCA & EF536003 \\
\hline GP5-R & AATT-GGATCC ${ }^{\text {a)_CTAAGGACGACCCCATTGTT }}$ & EF536003 \\
\hline aroA-F-XhoI & 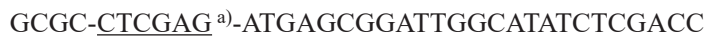 & AF182427 \\
\hline Kan- $B g l I I-F$ & 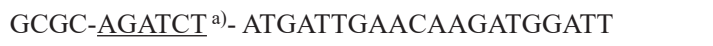 & AY048744 \\
\hline aroA-R-HindIII & 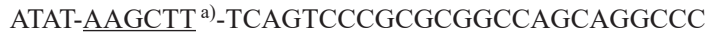 & AF182427 \\
\hline SYBR-F & GCTGATTTACAACTTGACGCTATG & EF536003 \\
\hline SYBR-R & AAGGAAATGGCTGGTAGTGAGG & EF536003 \\
\hline
\end{tabular}

a) Underlined: restriction enzyme sites.

They were transformed with insert DNA (aroA-F-kan ${ }^{\mathrm{R}}-\mathrm{GP5}$ aroA-R2) by electroporation (Gene Pulser Xcell ${ }^{\mathrm{TM}}$ electroporation system, Bio-Rad, Hercules, CA, U.S.A.) according to the manufacturer's instructions. Knock-out mutants were selected on Luria-Bertani plates containing $50 \mu \mathrm{g} / \mathrm{m} l$ of kanamycin.

PCR verification: Three PCRs were performed to verify that all mutants had the correct structures. Genomic DNA was prepared from a mutant colony and used as PCR template $(50 \mathrm{ng} / \mu \mathrm{l})$. Expected sizes and targets of the three PCRs are shown in Fig. 2. Primers, aroA-F-XhoI and GP5-R were used for PCR 1. Kan-BglII-F and aroA-R-HindIII were used for PCR 2. GP5-F and aroA-R-HindIII were used for PCR 3. Primers for PCR verification are listed in Table 1.

Expression of PRRSV GP5 in B. bronchiseptica: A single colony of mutant B. bronchiseptica carrying PRRSV GP5 (BBS-GP5) was grown in brain heart infusion broth. Cells were pelleted and lysed in $2 \times$ sodium dodecyl sulfatesample buffer (Sigma-Aldrich, St. Louis, MO, U.S.A.). Cell supernatants were subjected to $10 \%$ polyacrylamide gel electrophoresis and transferred onto polyvinylidene fluoride membrane (Bio-Rad). GP5-specific antibody (Ab) [12] in 1:100 dilution was used as primary $\mathrm{Ab}$. Horseradish peroxi- dase-conjugated goat anti-rabbit IgG Ab (Pierce, Rockford, IL, U.S.A.) at 1:1,000 dilution was used as secondary Ab. Expressed protein was visualized using diaminobenzidine substrate buffer and diaminobenzidine (Serotec, Oxford, U.K.) according to manufacturer's instructions.

Mouse immunization: A total of 9 eight-week-old female ICR mice (Charles River, Yokohama, Japan) were divided into 3 groups. All groups were primed subcutaneously (SC) with $50 \mu \mathrm{g}$ of recombinant GP5 (rGP5) [12] mixed with Freund's complete adjuvant (FCA) followed by boosting with different antigens (Table 2). For boosting with BBSGP5, mice were administered $1 \times 10^{5}$ colony forming units of freshly prepared overnight cultures. Blood samples were collected from tail veins every 7 days post-immunization (dpi), inactivated at $56^{\circ} \mathrm{C}$ for $30 \mathrm{~min}$ and stored at $-80^{\circ} \mathrm{C}$ until analyzed. Blood samples before experiments ( -1 dpi) were collected as negative controls.

Detection of PRRSV GP5-specific Abs: Enzyme-linked immunosorbent assay (ELISA) was used to determine the induction of IgG (sera) by heterologously expressed PRRSV GP5 in BBS-GP5 as described previously [12]. Briefly, 96well plates (Maxisorp ${ }^{\mathrm{TM}}$, Nunc, Roskilde, Denmark) were coated with rGP5 of PRRSV $(1 \mu \mathrm{g} /$ well/90 $\mu l)$ expressed in 


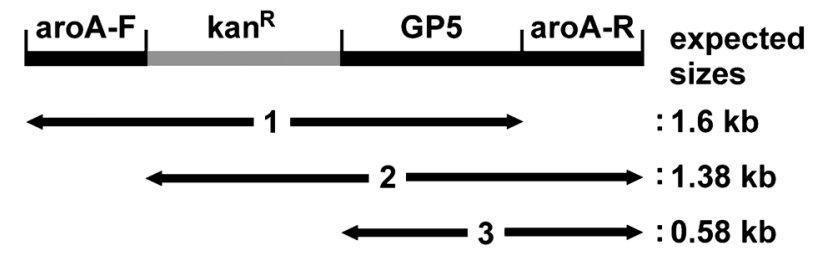

Fig. 2. Diagram of polymerase chain reaction (PCR) verification for genomic structure. The expected sizes and targets of three PCRs (1-3) are indicated.
Table 2. Group immunization schedule in mice

\begin{tabular}{cccc}
\hline Day & 0 & 14 & 28 \\
\hline Group 1 & rGP5+FCA $^{\text {a) }}$ SC & PBS & PBS \\
Group 2 & rGP5+FCA $^{\text {a) }}$ SC & rGP5+FIA $^{\text {b) SC }}$ & BBS-GP5 SC \\
Group 3 & rGP5+FCA $^{\text {a) SC }}$ & BBS-GP5 SC & BBS-GP5 SC \\
\hline
\end{tabular}

After initial priming with rGP5, mice were boosted with rGP5 or live BBS-GP5 via subcutaneous (SC) route. Controls (group 1) received only phosphate buffered saline (PBS). a) Freund's complete adjuvant (FCA); b) Freund's incomplete adjuvant (FIA).

Table 3. Immunization and challenge schedule for intramuscularly immunized pigs

\begin{tabular}{cccc}
\hline Day & Group 1 (positive immunization) & Group 2 (experimental) & Group 3 (negative immunization) \\
\hline 0 & rGP5 200 $\mu \mathrm{g}$ in PBS + FCA & rGP5 $200 \mu \mathrm{g}$ in PBS + FCA & rGP5 $200 \mu \mathrm{g}$ in PBS + FCA \\
14 & rGP5 200 $\mu \mathrm{g}$ in PBS + FIA & $1 \times 10^{8} \mathrm{BBS}-\mathrm{GP} 5 / \mathrm{kg}$ & $1 \times 10^{8} \mathrm{BBS}-\operatorname{aroA}^{\mathrm{a})} / \mathrm{kg}$ \\
21 & & Blood sampling and IgG titration & \\
28 & rGP5 200 $\mu \mathrm{g}$ in PBS + FIA & $1 \times 10^{8} \mathrm{BBS}-\mathrm{GP} 5 / \mathrm{kg}$ & $1 \times 10^{8} \mathrm{BBS}-\operatorname{aroA}^{\mathrm{a})} / \mathrm{kg}$ \\
35 & & Blood sampling and IgG titration & \\
42 & & PRRSV challenge & \\
47 & & Blood sampling and IgG titration & \\
\hline
\end{tabular}

a) Attenuated B. bronchiseptica aroA mutant [6].

E. coli [12]. Plates were blocked with phosphate buffered saline (PBS) containing 1\% skim milk and washed with PBS-T (PBS $+0.05 \%$ Tween 20). The sera for IgG analysis were prepared at 1:100 dilution based on previous optimization. The Ab samples in $90 \mu l$ of PBS-T were incubated at $37^{\circ} \mathrm{C}$ for $1 \mathrm{hr}$, emptied and washed three times with PBS-T. Bound IgG was detected using HRP-conjugated goat antimouse IgG (Serotec) diluted at 1:500. Secondary Ab was incubated at $37^{\circ} \mathrm{C}$ for $1 \mathrm{hr}$, emptied and washed three times with PBS-T. The presence of any bound secondary Ab was detected using substrate solution containing $0.1 \mathrm{M}$ citric acid buffer, pH $4.0(10 \mathrm{~m} /)$, ABTS stock solution (ABTS $100 \mathrm{mg}$ in $4.5 \mathrm{~m} l$ distilled water) $(250 \mu l)$ and hydrogen peroxide (50 $\mu l$ ). Plates were incubated in the dark at room temperature for $15 \mathrm{~min}$. The absorbance was measured at $405 \mathrm{~nm}$ using an ELISA plate reader (Multiskan EX, Thermo LabSystems, Beverly, MA, U.S.A.). Results were expressed as average \pm standard deviation (SD) for end-point titers.

Pig immunization and challenge: The vaccine potential of BBS-GP5 was evaluated by immunizing pigs with BBS-GP5 followed by challenge with PRRSV VR2332. Briefly, nine 19- to 20-day-old pigs (weaned, from non-vaccinated sows) were randomly assigned to three groups. Before immunization, blood samples were collected to check the presence of maternal anti-PRRSV antibodies that might be delivered by maternal colostrum. Pigs were immunized and challenged as described in Table 3. Serum samples from piglets of specific pathogen free-sows were used as negative serum controls. Serum samples from piglets vaccinated with VR2332 were used as positive serum controls. HRP-conjugated goat antipig IgG (Pierce) diluted at 1:500 was used as secondary Ab. For viral challenge, VR2332 (10 $0^{5.9} \mathrm{TCID}$ each) was injected intramuscularly (IM) to each piglet. Animals were monitored for 5 days and euthanized.

Viral clearance: The presence of viral RNA in lymphoid tissues was examined by quantitative real-time PCR and interpreted as viral clearance. Viral total RNA from four lymph nodes (superficial inguinal, submandibular, mediastinal and medial iliac) was prepared as described previously [2] and used for cDNA synthesis. For quantitative comparison, $\mathrm{SYBR}^{\circledR}$ Green 1-based real-time PCR was performed using two primers (SYBR-F and SYBR-R, Table 1) and Exicycler $^{\text {TM }}$ quantitative thermal block (Bioneer, Daejeon, Korea). The mean threshold cycle $(\mathrm{Ct})$ numbers of vaccinated group and control group were compared. A numerical difference (n) in the $\mathrm{Ct}$ value suggested a $2^{\mathrm{n}}$ fold difference in RNA expression level.

Statistical analysis: Unless indicated separately, the significance of variation among different groups was determined by one-way ANOVA, and the difference among groups was determined by Dunnett's multiple comparisons test using GraphPad Instat ${ }^{\circledR}$ Software 3.05 (GraphPad Software, La Jolla, CA, U.S.A.).

Cloning and expression of PRRSV GP5 in B. bronchiseptica: Results of the three PCRs to verify the generation of correct structures are shown in Fig. 3. Heterologous expression of PRRSV GP5 in BBS-GP5 was detected by western blot using PRRSV GP5-specific Ab. An expected band at approximately $27 \mathrm{kDa}$ was detected (Fig. 4, lane 3).

$A b$ responses in mice and pigs: The $\mathrm{IgG}$ levels in mice serum samples in group 2 and group 3 were significantly $(P<0.001)$ high when compared to those in groups 1 (control) (Fig. 5). The level of IgG in immunized pigs (groups 1 and 2) was also increased after the final boosting $\left({ }^{*} P<0.01\right.$ and $* * P<0.05$ : significant; $* * * P<0.1$ : not significant in Fig. $6)$. 


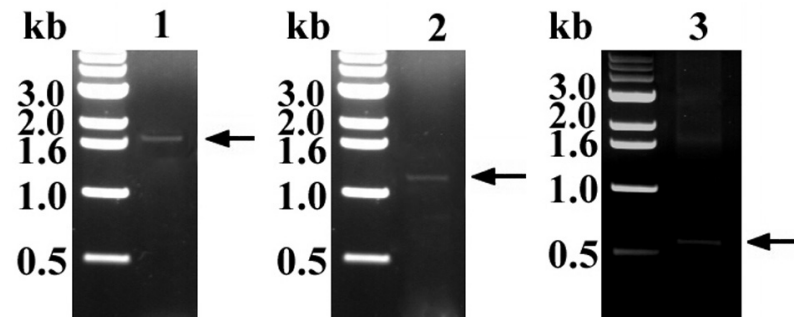

Fig. 3. Results of the three PCR verifications. Three expected PCR products indicating that correct structures were generated.

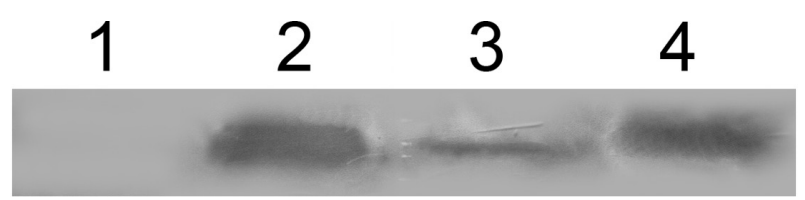

Fig. 4. Confirmation of the expression of heterologous porcine reproductive and respiratory syndrome virus (PRRSV) GP5 from BBS-GP5 by Western blotting. Bacterial lysate samples were reacted with GP5-specific Ab. Lane 1: BBS-aroA; lane 2: GP5expressing E. coli; lane 3: BBS-GP5; lane 4: purified rGP5.

Viral clearance: Quantitative real-time PCR revealed that the mean $\mathrm{Ct}$ value of superficial inguinal and medial iliac lymph node samples of the group 1 was significantly $(P<0.05)$ different from that of the group 3 (Table 4). Although insignificant by one-way ANOVA analysis, significantly higher $\mathrm{Ct}$ values (faster viral clearance) were also found in mediastinal and medial iliac lymph nodes in group 2 compared to those in group 3 by unpaired $t$-test.

Attenuated $B$. bronchiseptica has been used as vaccine vehicle to deliver heterologous antigens. To improve expression efficiency, bacterial expression vector has been employed [14-16]. Previously, we developed a BBS-aroA as a live vaccine vehicle for heterologous viral antigen expression (major capsid protein of porcine circovirus type 2) [6]. In this study, we used this mutant and heterologously expressed GP5 in an attempt to induce Ab production against viral antigen GP5. Due to limited amount of heterologously expressed recombinant proteins from attenuated bacterial vehicles, successful priming and/or boosting of animals using this method has not been promising so far. In our preliminary experiments, both priming and boosting with BBS-GP5 was not successful (very low boosting effect, data not shown). Therefore, we changed the priming procedure with purified rGP5. To overcome this issue, animals were primed with rGP5 (expressed from E. coli followed by purification) initially and boosted using the same recombinant antigens (rGP5 from E. coli or B. bronchiseptica vehicle) via parenteral (SC and/or IM) routes. As a result, immune responses (IgG induction) against rGP5 were successfully induced following the primary boosting step. Through reimmunizing (boost), we expected that the heterologous recombinant antigen expressed from BBS-GP5 via the

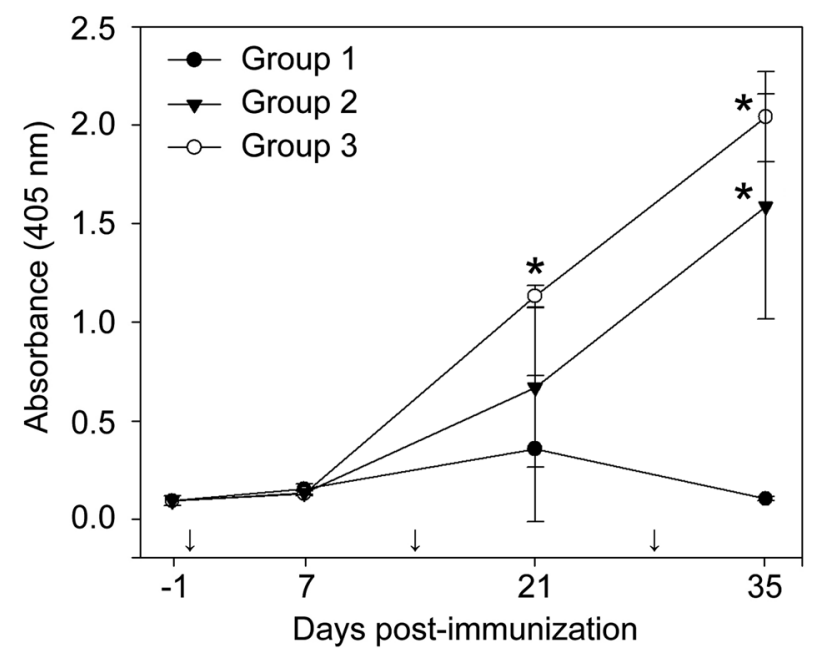

Fig. 5. Comparison of IgG levels (absorbance at $405 \mathrm{~nm}$ ) among mouse groups. A statistically significant increase $(* P<0.001)$ was observed in samples from 21 days post-immunization (dpi) for group 3 and 35 dpi for group 2 and group 3. Arrows showing time of immunization.

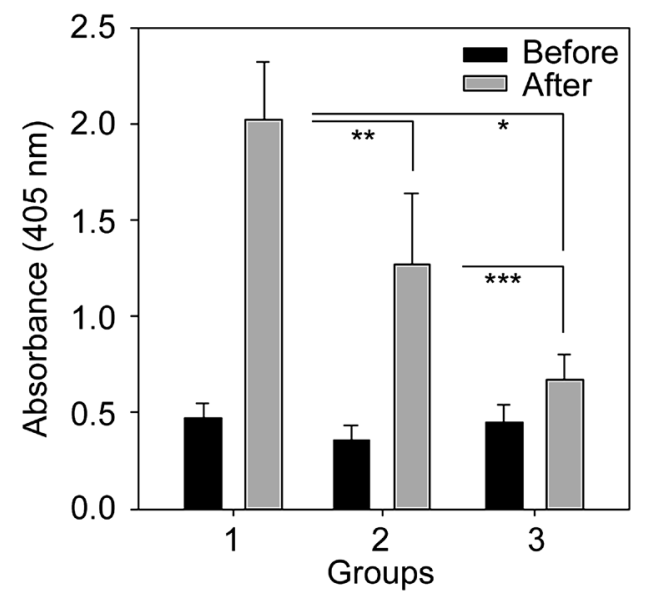

Fig. 6. Comparison of $\operatorname{IgG}$ levels (interpreted as absorbance at $405 \mathrm{~nm}$ ) among pig group before immunization (black) and after (grey) the final boosting. Noticeable increases were observed among groups. $(* P<0.01$ and $* * P<0.05$ : significant; $* * * P<0.1$ : not significant)

Table 4. Comparison of $\mathrm{Ct}$ values of lymph nodes using quantitative real-time PCR

\begin{tabular}{|c|c|c|c|}
\hline \multirow{2}{*}{ Lymph nodes } & \multicolumn{3}{|c|}{ Ct values \pm Standard deviation } \\
\hline & Group 1 & Group 2 & Group 3 \\
\hline Superficial inguinal & $30.71^{\text {a) }} \pm 3.26$ & $25.83 \pm 3.81$ & $21.74 \pm 1.83$ \\
\hline Submandibular & $24.23 \pm 0.95$ & $23.04 \pm 2.49$ & $22.01 \pm 2.45$ \\
\hline Mediastinal & $25.15 \pm 3.29$ & $26.18^{a)} \pm 1.58$ & $22.43 \pm 1.23$ \\
\hline Medial iliac & $27.58^{b)} \pm 2.12$ & $25.02^{a)} \pm 1.32$ & $21.65 \pm 1.20$ \\
\hline
\end{tabular}

a) $P<0.05$; b) $P<0.01$; Bold: unpaired $t$-test with two-tailed $P$ value. 
parenteral route could be recognized after bacterial clearance by phagocytes. This could result in the recognition of the same antigen by primed immunocytes. As a result, IgG levels were significantly increased after the parenteral administration of BBS-GP5. In mouse experiments, antibody was significantly $(P<0.001)$ induced in group 2 and group 3 . In pigs, an increase of IgG level (not significant, $P<0.1$ ) was also observed in group 2, although the IgG was lower than that of the pigs immunized and boosted with purified rGP5 (group 1 in Table 3). It appears that a sufficient amount of antigen for boosting is not likely to be produced by bacterial vehicle (BBS-GP5). However, once the antigen has been recognized and primed, heterologous recombinant antigen from the attenuated bacterial vehicle could be a good source for boosting reaction in host immune systems. Although we need to find a way to increase the amounts of heterologous antigens expressed, this bacterial vehicle system could be used to develop multivalent vaccine against PRRSV and $B$. bronchiseptica infection with reduced injection stresses.

CONFLICT OF INTEREST. All authors declare they do not have any conflict of interests.

\section{REFERENCES}

1. Ausubel, F. M., Brent, R., Kingston, R. E., Moore, D. D., Seidman, J. G., Smith, J. A. and Struhl, K. 2002. Short protocols in molecular biology. John Wiley \& Sons, New York.

2. Christopher-Hennings, J., Holler, L. D., Benfield, D. A. and Nelson, E. A. 2001. Detection and duration of porcine reproductive and respiratory syndrome virus in semen, serum, peripheral blood mononuclear cells, and tissues from Yorkshire, Hampshire, and Landrace boars. J. Vet. Diagn. Invest. 13: 133-142. [Medline] [CrossRef]

3. Datsenko, K. A. and Wanner, B. L. 2000. One-step inactivation of chromosomal genes in Escherichia coli K-12 using PCR products. Proc. Natl. Acad. Sci. U.S.A. 97: 6640-6645. [Medline] [CrossRef]

4. Delputte, P. L., Vanderheijden, N., Nauwynck, H. J. and Pensaert, M. B. 2002. Involvement of the matrix protein in attachment of porcine reproductive and respiratory syndrome virus to a heparinlike receptor on porcine alveolar macrophages. J. Virol. 76: 4312-4320. [Medline] [CrossRef]

5. Do, D. T., Park, C., Choi, K., Jeong, J., Nguyen, T. T., Nguyen, K. D., Vo, D. T. and Chae, C. 2015. Comparison of two genetically distant type 2 porcine reproductive and respiratory syndrome virus (PRRSV) modified live vaccines against Vietnamese highly pathogenic PRRSV. Vet. Microbiol. 179: 233-241. [Medline] [CrossRef]

6. Kim, T., Toan, N. T., Seo, J., Jung, B., Lee, J. and Lee, B. 2009. Bordetella bronchiseptica aroA mutant as a live vaccine vehicle for heterologous porcine circovirus type 2 major capsid protein expression. Vet. Microbiol. 138: 318-324. [Medline] [CrossRef]
7. Mardassi, H., Massie, B. and Dea, S. 1996. Intracellular synthesis, processing, and transport of proteins encoded by ORFs 5 to 7 of porcine reproductive and respiratory syndrome virus. Virology 221: 98-112. [Medline] [CrossRef]

8. Meulenberg, J. J., Petersen-den Besten, A., De Kluyver, E. P., Moormann, R. J., Schaaper, W. M. and Wensvoort, G. 1995. Characterization of proteins encoded by ORFs 2 to 7 of Lelystad virus. Virology 206: 155-163. [Medline] [CrossRef]

9. Ostrowski, M., Galeota, J. A., Jar, A. M., Platt, K. B., Osorio, F. A. and Lopez, O. J. 2002. Identification of neutralizing and nonneutralizing epitopes in the porcine reproductive and respiratory syndrome virus GP5 ectodomain. J. Virol. 76: 4241-4250. [Medline] [CrossRef]

10. Plagemann, P. G. 2004. GP5 ectodomain epitope of porcine reproductive and respiratory syndrome virus, strain Lelystad virus. Virus Res. 102: 225-230. [Medline] [CrossRef]

11. Plagemann, P. G., Rowland, R. R. and Faaberg, K. S. 2002. The primary neutralization epitope of porcine respiratory and reproductive syndrome virus strain VR-2332 is located in the middle of the GP5 ectodomain. Arch. Virol. 147: 2327-2347. [Medline] [CrossRef]

12. Pyo, H., Seo, J., Suh, G., Kim, K., Lee, J. and Kim, T. 2010. Serodiagnosis of porcine reproductive and respiratory syndrome virus infection with the use of glycoprotein 5 antigens. Can. J. Vet. Res. 74: 223-227. [Medline]

13. Sambrook, J. and Russell, D. W. 2001. Molecular Cloning: A Laboratory Manual. Cold Spring Harbor Laboratory Press, New York.

14. Stevenson, A. and Roberts, M. 2002. Use of a rationally attenuated Bordetella bronchiseptica as a live mucosal vaccine and vector for heterologous antigens. Vaccine 20: 2325-2335. [Medline] [CrossRef]

15. Stevenson, A. and Roberts, M. 2003. Use of Bordetella bronchiseptica and Bordetella pertussis as live vaccines and vectors for heterologous antigens. FEMS Immunol. Med. Microbiol. 37: 121-128. [Medline] [CrossRef]

16. Stevenson, A. and Roberts, M. 2004. Intranasal immunisation against tetanus with an attenuated Bordetella bronchiseptica vector expressing FrgC: improved immunogenicity using a Bvgregulated promoter to express FrgC. Vaccine 22: 4300-4305. [Medline] [CrossRef]

17. Thuy, N. T., Thu, N. T., Son, N. G., Ha, T. T., Hung, V. K., Nguyen, N. T. and Khoa, V. A. 2013. Genetic analysis of ORF5 porcine reproductive and respiratory syndrome virus isolated in Vietnam. Microbiol. Immunol. 57: 518-526. [Medline]

18. Xiong, D., Song, L., Zhai, X., Geng, S., Pan, Z. and Jiao, X. 2015. A porcine reproductive and respiratory syndrome virus (PRRSV) vaccine candidate based on the fusion protein of PRRSV glycoprotein 5 and the Toll-like Receptor-5 agonist Salmonella Typhimurium FljB. BMC Vet. Res. 11: 121. [Medline] [CrossRef]

19. Zhao, H., Wang, Y., Ma, Z., Wang, Y. and Feng, W. H. 2014. Recombinant Kluyveromyces lactis expressing highly pathogenic porcine reproductive and respiratory syndrome virus GP5 elicits mucosal and cell-mediated immune responses in mice. J. Vet. Sci. 15: 199-208. [Medline] [CrossRef] 